\title{
QUANTUM LEARNING SEBAGAI PROSES \\ PEMBELAJARAN BAHASA ARAB AKTIF, INOVATIF, KREATIF, EFEKTIF DAN MENYENANGKAN
}

\author{
Awaliah Musgamy \\ Fakultas Syariah dan Hukum Universitas Islam Negeri (UIN) Alauddin Makassar
}

\begin{abstract}
Arabic learning should be applied as an active, innovative, creative, effective and fun learning process to overcome the sluggishness of Arabic learning during this time. The greatest task a teacher must undertake is to change students' perceptions that Arabic is difficult and includes a scourge for them so that the application of active, innovative, creative, and fun learning is expected to eliminate the student stereotype by itself. Quantum Learning assumes that the learning process is like an orchestra incorporated from several components but capable of generating the entertaining notes of those not only those incorporated in the orchestra but including those around them. Therefore, to realize an active, innovative, creative, effective and fun Arabic learning, all the potential that exists in learning Arabic should be maximized.
\end{abstract}

\section{Keywords:}

Quantum Learning, Learning, Arabic

\begin{abstract}
Abstrak
Pembelajaran bahasa Arab harus diaplikasikan sebagai suatu proses pembelajaran yang aktif, inovatif, kreatif, efektif dan menyenangkan untuk mengatasi kelesuan pembelajaran bahasa Arab selama ini. Tugas terbesar yang harus dilakukan oleh seorang guru adalah mengubah persepsi para siswa bahwa bahasa Arab itu sulit dan termasuk momok bagi mereka sehingga penerapan pembelajaran yang aktif, inovatif, kreatif, dan menyenangkan diharapkan akan menghilangkan sterotip siswa tersebut dengan sendirinya.

Quantum Learning mengasumsikan bahwa proses pembelajaran seperti sebuah orkestra yang tergabung dari beberapa komponen tapi mampu menghasilkan alunan nada yang menghibur bukan hanya mereka yang tergabung dalam orkestra tersebut tapi termasuk mereka yang ada di sekitarnya. Oleh karena itu, untuk mewujudkan pembelajaran bahasa Arab yang yang aktif, inovatif, kreatif, efektif dan menyenangkan, segala potensi yang ada dalam pembelajaran bahasa Arab harus dimaksimalkan.
\end{abstract}

Kata Kunci:

Quantum Learning, Pembelajaran, Bahasa Arab 


\section{PENDAHULUAN}

ejauh ini belum ada hasil penelitian yang memastikan sejak kapan studi Islam di Indonesia mulai dirintis dan dikembangkan. Asumsi yang selama ini $\checkmark$ berkembang adalah bahwa studi Islam sudah mulai dikenal oleh bangsa Indonesia sejak Islam dikenal dan dianut oleh mayoritas bangsa kita. Jika Islam secara meluas telah dianut oleh masyarakat kita pada abad ke-13, maka usia studi Islam dipastikan sudah lebih dari 7 abad. Karena perjumpaan umat Islam Indonesia dengan studi Islam itu paralel dengan perjumpaannya dengan Islam. ${ }^{1}$ Kenyataan menunjukkan bahwa studi Islam telah memasuki masa yang sudah cukup untuk dikatakan matang dari sisi usia sehingga secara logis bisa dikatakan bahwa kematangan usia tersebut sudah sepantasnya menjadikan pengajaran dan pembelajaran studi Islam di Indonesia dapat berjalan secara lebih aktif, inovatif, kreatif, efektif, dan menyenangkan.

Namun, kenyataan di lapangan tidak berbanding lurus dengan asumsi diatas. Harapan akan pembelajaran studi Islam yang lebih aktif, inovatif, kreatif, efektif, dan menyenangkan ibarat jauh panggang dari api. Suasana pembelajaran yang lesu, stagnan, serta kurang menyenangkan menjadi pemandangan sehari-hari dalam pembelajaran studi Islam baik di sekolah-sekolah agama ataupun di sekolah-sekolah umum, itu kalau kita enggang mengatakan lebih-lebih. ${ }^{2}$ Padahal secara teoritis, pembelajaran bahasa Arab memiliki empat orientasi yang bisa dikatakan cukup berat, yaitu:

1. Orientasi Religius, yaitu belajar bahasa Arab untuk tujuan memahami ajaran Islam yang dalam hal ini al-Qur'an dan as-Sunnah.

2. Orientasi Akademik, yaitu belajar bahasa Arab untuk tujuan memahami ilmuilmu dan keterampilan berbahasa Arab. Orientasi ini cenderung menempatkan bahasa Arab sebagai disiplin ilmu yang harus dikuasai secara akademik. Orientasi ini biasanya identik dengan studi bahasa Arab pada berbagai lembaga pendidikan.

3. Orientasi Profesional dan Pragmatis, yaitu belajar bahasa Arab untuk kepentingan profesi, praktis atau pragmatis, seperti untuk menjadi TKI, diplomat, turis, misi dagang, atau untuk melanjutkan studi di salah satu negara Timur Tengah, dan semacamnya.

4. Orientasi Ideologis dan Ekonomis ${ }^{3}$, yaitu belajar bahasa Arab untuk memahami dan menggunaakan bahasa Arab sebagai media bagi kepentingan orientalisme,

1 Muhbib Abdul Wahab, Tantangan dan Prospek Pembelajaran Bahasa Arab di Indonesia, Arabic Translation and Intercultural Dialogue Association, www.atida.org. (06 Oktober 2011)

${ }^{2}$ Salah satu indikator adanya permasalahan dengan pembelajaran bahasa Arab adalah untuk mempelajari bahasa ini, waktu yang diperlukan cenderung lama, dimana hal tersebut jarang didapatkan pada pembelajaran bahasa Inggris misalnya. Lihat Ahmad Syalabi, Ta’tim al-Lugah al-Arabiyah lil Ghairil Arab (Kairo: Maktabah an-Nahdah al-Mishriyah, 1980), h. 18.

${ }^{3}$ Penulis melihat bahwa orientasi pembelajaran bahas Arab yang keempat ini cenderung pada tergambar dalam konteks pembalajaran bahasa Arab di luar Indonesia, meskipun manakala ada yang mempelajari bahasa 
kapitalisme, imperialisme, dan semacamnya. Orientasi ini, antara lain, terlihat dengan dibukanya beberapa lembaga kursus bahasa Arab di negara-negara Barat. $^{4}$

Dalam memacu pencapain orientasi-orientasi tersebut, maka diperlukan berbagai metode yang dapat memacu pembelajaran bahasa Arab sehingga bisa menjadi suatu pembelajaran yang lebih aktif, inovatif, kreatif, efektif, dan menyenangkan. Kehadiran Quantum Learning adalah ibarat pancaran air penyubur tanah di tengah padang sahara pembelajaran bahasa Arab yang kering dan tandus. Namun, penerapan Quantum Learning tidak akan berjalan dengan efektif dan efisien sebagai media pengantar materi pengajaran bila penerapannya tanpa didasari dengan pengetahuan yang memadai tentang metode itu. Bahkan, metode bisa saja akan menjadi penghambat jalannya proses pembelajaran jika aplikasinya tidak tepat.

Berdasarkan gambaran diatas, beberapa permasalahan dapat dirumuskan sebagai berikut:

1. Bagaimana gambaran umum tentang Quantum Learning?

2. Bagaimana urgensi pembelajaran aktif, inovatif, kreatif, efektif, dan menyenangkan (PAIKEM) dalam proses pembelajaran bahasa Arab?

3. Bagaimana penerapan Quantum Learning dalam mewujudkan pembelajaran bahasa Arab yang aktif, inovatif, kreatif, efektif, dan menyenangkan?

\section{PEMBAHASAN}

\section{A. Gambaran Umum tentang Quantum Learning}

Septiawan Santana Kurnia menggambarkan Quantum Learning sebagai Quantum Learning ialah kiat, petunjuk, strategi, dan seluruh proses belajar yang dapat mempertajam pemahaman dan daya ingat, serta membuat belajar sebagai suatu proses yang menyenangkan dan bermanfaat. Beberapa teknik yang dikemukakan merupakan teknik meningkatkan kemampuan diri yang sudah populer dan umum digunakan. Namun, Bobbi DePorter mengembangkan teknikteknik yang sasaran akhirnya ditujukan untuk membantu para siswa menjadi responsif dan bergairah dalam menghadapi tantangan dan perubahan realitas. ${ }^{5}$ Dengan kesuksesan membekali kesiapan pada siswa dalam menghadapi tantangan dan perubahan realitas, seorang guru telah berhasil melejitkan potensi siswa tersebut untuk melakukan aktivitas-aktivitas pembelajaran yang merupakan loncatan berpikir dan bertindak beberapa langkah lebih maju dibanding siswa yang lainnya.

Sejalan dengan pendapat diatas, R. Teti Rostikawati menggambarkan Quantum Learning pada salah satu abstrak tulisannya sebagai berikut:

Arab di Indonesia untuk tujuan tersebut, tidak serta-merta bisa dijustifikasi bahwa orientasi tersebut termasuk orientasi pembelajaran bahasa Arab di Indonesia.

${ }^{4}$ Ibid.

5 Saptiawan Santana Kurnia, Quantum Learning bagi Pendidikan Jurnalistik: (Studi pembelajaran jurnalistik yang berorientasi pada life skill), http://akhmadsudrajat.wordpress.com. (25 Mei 2009) 
"There are a lot of ways of solving the problems in the failure of Educational System. Innovations in the learning methods that may develop students' academic and creative potentials have been attempted. One of the methods recently developed in schools is Quantum Learning Method. Students' positive suggestions will bring about high motivation resulting in potential development and excellent achievement at school and in the society in the future" 6

Apa yang digambarkan diatas menunjukkan bahwa potensi terbesar yang terdapat pada Quantum Learning ini adalah para siswa diberikan sugesti positif untuk memacu motivasi belajar mereka sehingga terwujud pencapaian yang luar biasa dalam sekolah dan masyarakat dimana mereka berada. Hal tersebut tidak terlepas dengan apa yang diungkapkan oleh Bobby DePorter dan Mike Hernacki yang mengatakan bahwa Quantum Learning berakar dari upaya Georgi Lozanov yang melakukan eksperimen yang disebut suggestology (suggestopedia). Prinsipnya adalah bahwa sugesti dapat mempengaruhi hasil situasi belajar, dan setiap detil apa pun memberikan sugesti positif atau negatif. Untuk mendapatkan sugesti positif, para murid di dalam kelas dibuat menjadi nyaman. Musik dipasang, partisipasi mereka didorong lebih jauh. Poster-poster besar yang menonjolkan informasi ditempel, dan menyediakan guru-guru yang telah terlatih baik dalam seni pengajaran sugestif.7 Ini menunjukkan bahwa bahawa dalam proses pembelajaran yang menggunakan Quantum Learning sebagai metode dalam prosesnya, pembelajaran tidak dipandang dalam arti sempit sebagai interaksi timabal baik seorang guru dengan para siswanya, tapi lebih dari itu semua yang ada dalam lingkungan pembelajaran akan berbunyi untuk memberikan sugesti bagi para siswa untuk memacu percepatan daya tangkap mereka terhadap proses pembelajaran yang berlangsung.

Berdasarkan asumsi diatas, Bobby DePorter dan Mike Hernacki menegaskan bahwa prinsip suggestology hampir mirip dengan proses accelerated learning, pemercepatan belajar: $^{8}$ yakni, proses belajar yang memungkinkan siswa belajar dengan kecepatan yang mengesankan, dengan upaya yang normal, dan dibarengi kegembiraan. Suasana belajar yang efektif diciptakan melalui campuran antara lain unsur-unsur hiburan, permainan, cara berpikir positif, dan emosi yang sehat. ${ }^{9}$ Keterkaitan antara suggestology dan accelerated learning tentunya dipahami bahwa

\footnotetext{
${ }^{6}$ R. Teti Rostikawati, Mind Mapping dalam Metode Quantum Learning dan Pengaruhnya terhadap Prestasi Belajar dan Kreatifitas Siswa. http://pkab.wordpress.com (06 Oktober 2011)

${ }^{7}$ Bobby DePorter dan Mike Hernacki, Quantum Learning: Unleashing the Genius in You, diterjemahkan oleh Alwiyah Abdurrahman, Quantum Learning: Membiasakan Belajar Nyaman dan Menyenangkan (Cet. XXV; Bandung: Kaifa, 2007), h. 14.

${ }^{8}$ Pemercepatan belajar adalah upaya menyingkirkan hambatan yang menghalangi proses belajar secara alamiah dengan secara sengaja menggunakan musik, mewarnai lingkungan sekeliling, menyusun bahan pengajaran yang sesuai, dan keterlibatan aktif. Lihat Bobby DePorter dkk., Quantum Teaching: Orchestrating Student Success, diterjemahkan oleh Ary Nilandari, Quantum Teaching: Mempraktikkan Quantum Learning di Ruang-Ruang Kelas (Cet. XI; Bandung: Kaifa, 2003), h. 5.

${ }^{9}$ Ibid., h. 14.
} 
seorang siswa yang telah mendapatkan suggesti positif untuk belajar cenderung akan menjadi mandiri dalam memacu dirinya sendiri.

Dalam kaitannya dengan otak, Quantum Learning juga tidak bisa dilepaskan mencakup aspek-aspek penting dalam program neurolinguistik (NLP), yaitu suatu penelitian tentang bagaimana otak mengatur informasi. Program ini meneliti hubungan antara bahasa dan perilaku dan dapat digunakan untuk menciptakan jalinan pengertian siswa dan guru. Para pendidik dengan pengetahuan NLP mengetahui bagaimana menggunakan bahasa yang positif untuk meningkatkan tindakan-tindakan posistif untuk merangsang fungsi otak yang paling efektif. Semua ini dapat pula menunjukkan dan menciptakan gaya belajar terbaik dari setiap orang. ${ }^{10}$

Lebih lanjut, Bobby DePorter dan Mike Hernacki mendefinisikan Quantum Learning sebagai interaksi-interaksi yang mengubah energi menjadi cahaya. Mereka mengamsalkan kekuatan energi sebagai bagian penting dari tiap interaksi manusia. Dengan mengutip rumus klasik $\mathrm{E}=\mathrm{mc}^{2}$, mereka alihkan ihwal energi itu ke dalam analogi tubuh manusia yang secara fisik adalah materi. "Sebagai pelajar, tujuan kita adalah meraih sebanyak mungkin cahaya: interaksi, hubungan, inspirasi agar menghasilkan energi cahaya". Pada kaitan inilah, Quantum Learning menggabungkan sugestologi, teknik pemercepatan belajar, dan NLP dengan teori, keyakinan, dan metode tertentu. Termasuk konsep-konsep kunci dari teori dan strategi belajar, seperti: teori otak kanan/kiri, teori otak triune (3 in 1), pilihan modalitas (visual, auditorial, dan kinestik), teori kecerdasan ganda, pendidikan holistik, belajar berdasarkan pengalaman, belajar dengan simbol (metaphoric learning), dan simulasi/permainan. ${ }^{11}$

Namun suatu hal yang tidak bisa dipungkiri bahwa Quantum Learning hanya akan dapat memberikan kontribusi maksimal jika paradigma yang melingkupinya dianut oleh guru dan siswa yang terlibat langsung dalam interkasi pembelajaran. Paradigma yang harus dipegang oleh guru dan para siswa dalam proses pembelajaran dengan Quantum Learning adalah:

1. Setiap orang adalah guru dan sekaligus murid sehingga bisa saling berfungsi sebagai fasilitator

2. Bagi kebanyakan orang belajar akan sangat efektif jika dilakukan dalam suasana yang menyenangkan, lingkungan dan suasana yang tidak terlalu formal, penataan duduk setengah melingkar tanpa meja, penataan sinar atau cahaya yang baik sehingga peserta merasa santai dan relaks.

3. Setiap orang mempunyai gaya belajar, bekerja dan berpikir yang unik dan berbeda yang merupakan pembawaan alamiah sehingga tidak perlu dirubah. Dengan demikian, perasaan nyaman dan positif akan terbentuk dalam menerima informasi atau materi yang diberikan oleh fasilitator.

\footnotetext{
10 Ibid.

${ }^{11}$ Ibid., h. 16.
} 
4. Modul pelajaran tidak harus rumit tapi harus dapat disajikan dalam bentuk sederhana dan lebih banyak ke suatu kasus nyata atau aplikasi langsung.

5. Dalam menyerap dan mengolah informasi otak menguraikan dalam bentuk simbol atau asosiatif sehingga materi akan lebih mudah dicerna bila lebih banyak disajikan dalam bentuk gambar, diagram, flow atau simbol.

6. Kunci menuju kesuksesan model Quantum Learning adalah latar belakang (background) musik klasik atau instrumental yang telah terbukti memberikan pengaruh positip dalam proses pembelajaran. Musik klasik dari Mozart, bach, Bethoven, dan Vivaldi dapat meningkatkan kemampuan mengingat, mengurangi stress, meredakan ketegangan, meningkatkan energi dan membesarkan daya ingat. Musik menjadikan orang lebih cerdas.

7. Penggunaan Warna dalam model Quantum Learning dapat meningkatkan daya tangkap dan ingat sebanyak $78 \%$.

8. Metode peran dimana peserta berperan lebih aktif dalam membahas materi sesuai dengan pengalamannya melalui pendekatan terbalik yaitu membuat belajar serupa bekerja (pembelajaran orang dewasa)

9. Sistim penilaian yang disarankan untuk abad 21 dalam pembelajaran adalah $50 \%$ penilaian diri sendiri, 30\% penilaian teman, $20 \%$ penilaian trainer atau atasan.

10. Umpan balik yang positif akan mampu memotivasi anak untuk berprestasi namun umpan balik negative akan membuat anak menjadi frustasi. Ini berdasar hasil riset pakar masalah kepercayaan diri, Jack Carfiled pada tahun 1982. 100 anak ditunjuk oleh periset selam sehari. Hasilnya, bahwa setiap anak rata-rata menerima 460 komentar negatif dan hanya 75 komentar positif. ${ }^{12}$

\section{B. Urgensi Pembelajaran Aktif, Inovatif, Kreatif, dan Menyenangkan (PAIKEM) dalam Proses Pembelajaran Bahasa Arab}

Sebagaimana diketahui bahwa keberhasilan suatu proses pembelajaran tidak bisa dilepaskan dari berbagai aspek yang saling berinteraksi satu sama lain dan melingkupi proses pedagogis tersebut. Suatu hal yang perlu dijadikan acuan bahwa jika ada iklan yang mengatakan "apapun makanannya, Teh Botol Sosro minumannya", maka dalam pembelajaran bisa dikatakan "apapun materinya, pembelajarannya harus aktif, inovatif, kreatif, efektif, dan menyenangkan."

Dalam menggambarkan Pembelajaran Aktif, Inovatif, Kreatif, Efektif, dan Menyenangkan (PAIKEM), A. Tarmizi Ramadhan menjelaskan tiap-tiap item dari term tersebut sebagai berikut:

1. Pembelajaran bahasa Arab aktif berarti bahwa dalam proses pembelajaran guru harus menciptakan suasana sedemikian rupa sehingga siswa aktif bertanya, mempertanyakan, dan mengemukakan gagasan.

${ }^{12}$ Guruvalah, Quantum Learning Melejitkan Potensi Anda, dikutip dari Artikel Majalah Sang Surya, Samarinda Kalimantan Timur, http://www.geocities.com. (06 Oktober 2011) 
2. Pembelajaran bahasa Arab inovatif bisa mengadaptasi dari model pembelajaran yang menyenangkan. Learning is fun merupakan kunci yang diterapkan dalam pembelajaran inovatif. Jika siswa sudah menanamkan hal ini di pikirannya, tidak akan ada lagi siswa yang pasif di kelas, perasaan tertekan dengan alokasi waktu tugas, kemungkinan kegagalan, keterbatasan pilihan, dan tentu saja rasa bosan. ${ }^{13}$

3. Pembelajaran bahasa Arab kreatif dimaksudkan agar guru menciptakan kegiatan belajar yang beragam sehingga memenuhi berbagai tingkat kemampuan siswa. Menyenangkan adalah suasana belajar-mengajar yang menyenangkan sehingga siswa memusatkan perhatiannya secara penuh pada belajar sehingga waktu curah perhatiannya (time on task) tinggi.

4. Pembelajaran bahasa Arab efektif mengasumsikan bahwa keadaan aktif dan menyenangkan tidaklah cukup jika proses pembelajaran tidak efektif, yaitu tidak menghasilkan apa yang harus dikuasai siswa setelah proses pembelajaran berlangsung, sebab pembelajaran memiliki sejumlah tujuan pembelajaran yang harus dicapai. Jika pembelajaran hanya aktif dan menyenangkan tetapi tidak efektif, maka pembelajaran tersebut tak ubahnya seperti bermain biasa.

5. Pembelajaran bahasa Arab menyenangkan dimaksudkan agar suasana proses pembelajaran bisa meminimalisir ketakutan-ketakutan siswa akan pembelajaran bahasa Arab. Tapi suatu hal yang harus dipertegas bahwa suasana menyenangkan tidak mesti mengkebiri sisi efektifitas pembelajaran bahasa Arab yang diadakan. ${ }^{14}$

Jadi bisa dilihat bahwa pembelajaran yang aktif, inovatif, kreatif, efektif, dan menyenangkan akan mewujudkan kondisi pembelajaran bahasa Arab yang bukan hanya memperhatikan aspek-aspek manusiawi para siswa, tapi juga tidak mengabaikan aspek-aspek pedagogis yang melingkupi proses pembelajaran tersebut. Tidak bisa dipungkiri bahwa perasaan tertekan dalam diri siswa begitu terasa dalam pembelajaran bahasa Arab. Suatu kenyataan yang jarang kita dapatkan dalam pembelajaran bahasa asing lainnya, bahasa Inggris misalnya. Padahal, manakala seorang guru telah gagal untuk menanamkan persepsi dalam diri para siswanya bahwa pembelajaran bahasa Arab itu adalah proses pembelajaran yang aktif, inovatif, kreatif, efektif, dan menyenangkan, sesungguhnya ia telah gagal untuk mengantarkan mereka pencapaian pembelajaran yang maksimal.

${ }^{13}$ Membangun metode pembelajaran inovatif sendiri bisa dilakukan dengan berbagai cara diantaranya mengakomodir setiap karakteristik diri. Artinya mengukur daya kemampuan serap ilmu masing-masing orang. Contohnya saja sebagian orang ada yang berkemampuan dalam menyerap ilmu dengan menggunakan visual atau mengandalkan kemampuan penglihatan, auditory atau kemampuan mendengar, dan kinestetik. Dan hal tersebut harus disesuaikan pula dengan upaya penyeimbangan fungsi otak kiri dan otak kanan yang akan mengakibatkan proses renovasi mental, diantaranya membangun rasa percaya diri para siswa.

14 A. Tarmizi Ramadhan, Pembelajaran Aktif, Inovatif, Kreatif, Efektif, dan Menyenangkan, http://tarmizi.wordpress.com. (06 Oktober 2011) 


\section{Penerapan Quantum Learning dalam Mewujudkan Pembelajaran Bahasa Arab yang Aktif, Inovatif, Kreatif, Efektif, dan Menyenangkan}

Kehadiran Quantum Learning telah memberikan angin segar dalam dunia pendidikan, termasuk pembelajaran termasuk bahasa Arab. Kehadiran Quantum Learning diharapkan mampu untuk membangunkan pembelajaran bahasa Arab dari kelesuan metode pembelajaran yang stagnan dalam mengikuti pembelajaran bahasa asing yang terus bergerak dinamis mengiringi perputaran masa.

Sebagai acuan dalam pembahasan tentang penerapan Quantum Learning dalam mewujudkan pembelajaran bahasa Arab yang aktif, inovatif, kreatif, efektif, dan menyenangkan, jika dikutip apa yang disampaikan oleh Djoko Saryono dimana ia mengungkapkan poin-poin tentang bagaimana pembelajaran dan para siswa diarahkan pada suatu simponi orkestra pembelajaran quantum sebagai berikut:

a. Pembelajaran berlangsung secara aktif jika siswa itu aktif dan kreatif. Bukti keaktifan dan kekreatifan itu dapat ditemukan pada fungsi otak kanan dan kiri siswa. Pembelajaran pasif cenderung mengingkari kenyataan bahwa siswa itu aktif dan kreatif sebagaimana mengingkari fungsi otak kiri dan kanan.

b. Pembelajaran berlangsung efektif dan optimal bila didasarkan pada gaya belajar siswa. Setidak-tidaknya ada tiga gaya belajar yang harus diperhitungkan dalam proses pembelajaran, yaitu gaya auditoris, gaya visual, dan gaya kinestesis.

c. Pembelajaran berlangsung efektif dan optimal bila tercipta suasana nyaman, menyenangkan, rileks, sehat, dan menggairahkan sehingga kenyamanan, kesenangan, kerileksan, dan kegairahan dalam pembelajaran perlu diciptakan dan dijaga. Oleh karena itu, baik lingkungan fisikal, lingkungan mental, dan suasana harus dirancang dan ditata sedemikian rupa agar membangkitkan kesan nyaman, rileks, menyenangkan, sehat, dan menggairahkan.

d. Pembelajaran melibatkan lingkungan fisikal-mental dan kemampuan pikiran atau potensi diri siswa secara serempak. Oleh karena itu, penciptaan dan pemeliharaan lingkungan yang tepat sangat penting. Dalam konteks inilah perlu dipelihara suasana positif, aman, suportif, santai, dan menyenangkan, dimana terdapat lingkungan fisik yang partisipatif, terbangunnya sikap saling menolong, ada permainan, dan semacamnya.

e. Pembelajaran membutuhkan keserasian konteks dan isi. Semua konteks pembelajaran perlu dikembangkan secara serasi dengan isi pembelajaran. Oleh karena itu, suasana pembelajaran yang memberdayakan, landasan yang kokoh, lingkungan fisikal-mental yang mendukung, serta rancangan pembelajaran yang dinamis, harus diciptakan. Selain itu, penyajian yang prima, fasilitasi yang lentur, keterampilan belajar yang merangsang untuk belajar, serta keterampilan hidup yang suportif juga harus dipelihara.

f. Pembelajaran berlangsung optimal apabila terdapat keragaman dan kebebasan. Oleh karena itu, keragaman dan kebebasan perlu diakui, dihargai, dan diakomodasi dala proses pembelajaran. Keseragaman dan ketertiban (dalam arti 
kekakuan) harus dihindari karena mereduksi dan menyederhanakan potensi dan karakteristik siswa. Potensi dan karakteristik siswa sangat beragam sehingga membutuhkan suasana bebas untuk beraktualisasi dan berartikulasi. ${ }^{15}$

Dalam proses pembelajaran bahasa Arab dengan menggunakan Quantum Learning, seorang guru harus meneliti karakteristik belajar para siswanya apakah termasuk pelajar visual, auditorial, ataukah kinestetik. Hal tersebut akan membantu guru dalam mencurahkan diri pada modalitas belajar terbaik mereka. ${ }^{16}$ Contoh sederhana yang bisa diambil adalah dalam pembelajaran materi bahasa Arab Imla', seorang siswa yang memiliki karakteristik belajar visual, dapat diajarkan Imla' dengan menggunakan media gambar sebagai penguatan (reinforcement) akan bacaan yang ditransfer secara oral. Sementara itu, bagi siswa yang memiliki belajar auditorial, Imla' bisa diberikan seperti biasa dengan cara dibacakan tapi bisa dimodifikasi dengan memperdengarkan musik lembut yang berfungsi sebagai penguatan (reinforcement) akan bacaan yang ditransfer secara oral. Seperti kalau mendiktekan bacaan tentang pertanian, maka rekaman suara seruling gembala bisa diperdengarkan dengan media tape recorder. Lain lagi ceritanya jika yang dihadapi adalah siswa yang memiliki karakteristik belajar kinestetik, guru bisa memacu pemahaman para siswa dengan mengawali pembelajaran Imla' mengajak mereka untuk bermain peran (role play) terlebih dahulu sebagai brainstorming yang akan memacu pemahaman mereka terhadap pembelajaran $I m l a^{\prime}$ yang diaplikasikan. ${ }^{17}$ Berapapun pencapaian mereka, guru hendaknya selalu menggunakan stimulusstimulus positif berupa pujian atau sanjungan.

Dalam rangka menyelaraskan konteks dengan substansi pembahasan pembelajaran bahasa Arab, Quantum Learning menegaskan perlunya panataan kondisi pembelajaran yang sejalan (matched) dengan topik bahasan. Suatu hal yang harus dipertegas disini adalah kesesuaian disini bukan hanya sebatas kesesuaian pada kondisi ruangan yang ukurannya hanya sekitar 10 × 10 meter, tapi mencakup konteks yang lebih luas dari pada itu yaitu konteks sosio-kultural dimana mereka akan menggunakan bahasa Arab tersebut.

\section{PENUTUP}

\section{A. Kesimpulan}

Berdasarkan pembahasan diatas, dapat ditarik beberapa kesimpulan sebagai berikut:

15 Djoko Saryono, Pembelajaran Quantum sebagai Model Pembelajaran yang Menyenangkan, http://www.microsoft.com. (06 Oktober 2011)

${ }^{16}$ Bobby Deporter dan Mike Hernacki, op.cit., h. 117.

17 Suatu hal yang harus dipedomani dalam pembelajaran bahasa Arab adalah bahwa perbedaanperbedaan yang melingkupi proses pembelajaran turut mewarnai pendekatan-pendekatan yang harus diambil. Lihat Mahmud Ismail Shīnī dkk., Mursyid al-Muallim fi Tadrīsi al-Lughah al-Arabiyah lil Ghairi an-Nātiqīna Biha, (Cet. II; Riyadh: Maktabah al-Tarbiyah al-Arabiyah lil Daūlil al-Halīj, 1985), h. 3. 
1. Quantum Learning adalah seperangkat metode dan falsafah belajar yang telah terbukti mampu melejitkan potensi belajar para siswa dengan melakukan penggabungan-penggabungan teori-teori pembelajaran seperti suggestology, teori otak kanan/kiri, pilihan modalitas (visual, auditorial, dan kinestetik), teori kecerdasan ganda, teori kecerdasan ganda, pendidikan holistik, belajar berdasarkan pengalaman, belajar dengan simbol (metaphoric learning), serta simulasi/permainan.

2. Pembelajaran bahasa Arab harus diaplikasikan sebagai suatu proses pembelajaran yang aktif, inovatif, kreatif, efektif dan menyenangkan untuk mengatasi kelesuan pembelajaran bahasa Arab selama ini. Tugas terbesar yang harus dilakukan oleh seorang guru adalah mengubah persepsi para siswa bahwa bahasa Arab itu sulit dan termasuk momok bagi mereka sehingga penerapan pembelajaran yang aktif, inovatif, kreatif, dan menyenangkan diharapkan akan menghilangkan sterotip siswa tersebut dengan sendirinya.

3. Quantum Learning mengasumsikan bahwa proses pembelajaran seperti sebuah orkestra yang tergabung dari beberapa komponen tapi mampu menghasilkan alunan nada yang menghibur bukan hanya mereka yang tergabung dalam orkestra tersebut tapi termasuk mereka yang ada di sekitarnya. Oleh karena itu, untuk mewujudkan pembelajaran bahasa Arab yang yang aktif, inovatif, kreatif, efektif dan menyenangkan, segala potensi yang ada dalam pembelajaran bahasa Arab harus dimaksimalkan.

\section{B. Implikasi}

Dari makalah yang merupakan hasil penangkapan daya pikir dan analisis penulis yang begitu terbatas ini, dapat dipahami bahwa metode tidak boleh menjadi penghalang bagi seorang pengajar untuk berkreasi demi mengajar. Adanya tuduhan bahwa pembelajaran bahasa Arab sudah ditakdirkan menjadi nomor urut sekian setelah bahasa Inggris membuat penulis curiga jangan-jangan itu hanya ungkapan mereka yang kurang kreatif (terlalu kaku memahami suatu metode) dalam mengajar kemudian lempar batu sembunyi tangan dengan menjadikan metode sebagai kambing hitam untuk mencari pembenaran dari keterbatasan kreatifitasnya. Logikanya, bagaimana mungkin output-nya bisa berbeda padahal apa yang disebut metode dalam pembelajaran bahasa Inggris dapat juga ditransfer ke dalam pembelajaran bahasa Arab, jadi apanya yang salah? Wallāhu a'lam! 


\section{Daftar Pustaka}

DePorter., Bobby dan Mike Hernacki, Quantum Learning: Unleashing the Genius in You, diterjemahkan oleh Alwiyah Abdurrahman, Quantum Learning: Membiasakan Belajar Nyaman dan Menyenangkan, Cet. XXV; Bandung: Kaifa, 2007.

DePorter., Bobby dkk., Quantum Teaching: Orchestrating Student Success, diterjemahkan oleh Ary Nilandari, Quantum Teaching: Mempraktikkan Quantum Learning di Ruang-Ruang Kelas, Cet. XI; Bandung: Kaifa, 2003.

Guruvalah, Quantum Learning Melejitkan Potensi Anda, dikutip dari Artikel Majalah Sang Surya, Samarinda Kalimantan Timur, http://www.geocities.com (06 Oktober 2011)

Kurnia., Saptiawan Santana, Quantum Learning bagi Pendidikan Jurnalistik: (Studi pembelajaran jurnalistik yang berorientasi pada life skill), http://akhmadsudrajat.wordpress.com. (06 Oktober 2011)

Rostikawati., R. Teti, Mind Mapping dalam Metode Quantum Learning dan Pengaruhnya terhadap Prestasi Belajar dan Kreatifitas Siswa. http://pkab.wordpress.com (06 Oktober 2011)

Ramadhan., A. Tarmizi, Pembelajaran Aktif, Inovatif, Kreatif, Efektif, dan Menyenangkan, http://tarmizi.wordpress.com. (06 Oktober 2011)

Saryono., Djoko, Pembelajaran Quantum sebagai Model Pembelajaran yang Menyenangkan, http://www.microsoft.com. (06 Oktober 2011)

Shīnī., Mahmud Ismail dkk., Mursyid al-Muallim fì Tadrīsi al-Lughah al-Arabiyah lil Ghairi an-Nātiqīna Biha, Cet. II; Riyadh: Maktabah al-Tarbiyah al-Arabiyah lil Daūli al-Halìj, 1985.

Syalabi., Ahmad, Ta'limm al-Lugah al-Arabiyah lil Ghairil Arab, Kairo: Maktabah anNahdah al-Mishriyah, 1980.

Wahab., Muhbib Abdul, Tantangan dan Prospek Pembelajaran Bahasa Arab di Indonesia, Arabic Translation and Intercultural Dialogue Association, www.atida.org (06 Oktober 2011) 